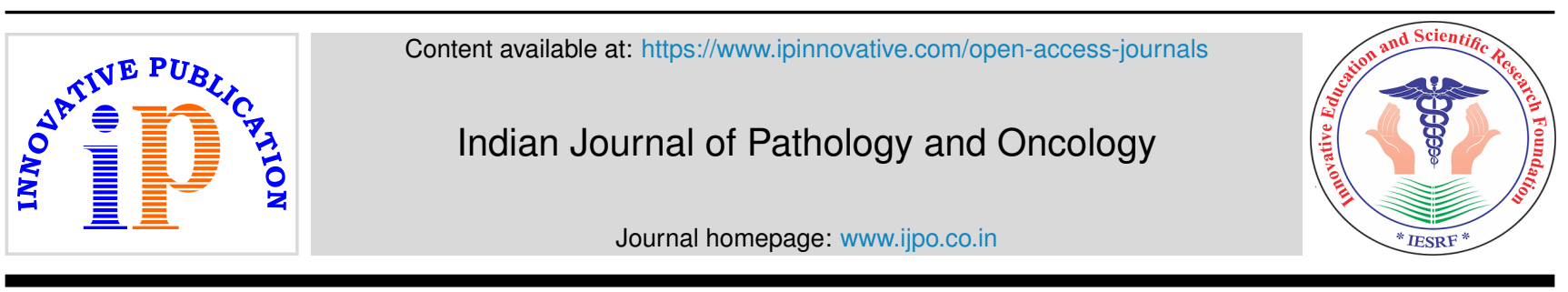

Original Research Article

\title{
A study of various diagnostic tests to identify offending allergens in patients of allergic rhinitis in a tertiary care centre in northern India
}

\author{
Pooja Arora ${ }^{1, *}$ \\ ${ }^{1}$ Dept. of Pathology, Government Medical College, Saharanpur, Uttar Pradesh, India
}

\section{A R T I C L E I N F O}

Article history:

Received 15-03-2021

Accepted 16-03-2021

Available online 19-05-2021

\section{Keywords:}

Allergic rhinitis

Skin prick test

Aeroallergens

Nasal smear eosinophils

$\operatorname{IgE}$

\begin{abstract}
A B S T R A C T
Background and Objectives: Allergic rhinitis, a global health issue, if left untreated cause serious conditions like asthma, sinusitis or ear infections. Precise identification of allergens is worthwhile since it may lead to improvement in therapy. Therefore, this study was undertaken to determine the common inhalant allergens causing allergy in and around Saharanpur by skin prick test, serum IgE levels, nasal smear eosinphilia and AEC levels.

Materials and Methods: 50 patients diagnosed clinically to have allergic rhinitis were included in the study. Absolute eosinophil count, nasal smear for eosinophils, and total IgE levels (wherever possible) were determined. Skin prick tests using 46 common inhalant allergens were done and results analysed. Results: Increased absolute eosinophil count, nasal smear positive for eosinophil and raised total IgE levels were found to be present in 56\%, 22\% and $97 \%$ of the patients respectively. Frequency of positive skin prick test response to various group of allergens were - Pollen (80\%), Dust (70\%), Mite (52\%), Insects (50\%), Fungi (48\%) and Epithelial antigens (20\%). Overall, pollen of Parthenium (in 70\%) followed by House dust (in 64\%) were found to be the most common offending allergens.

Conclusion: It can be concluded that skin prick test along with serum IgE levels used to identify the causative allergens is useful in the patients of allergic rhinitis.

(C) This is an open access article distributed under the terms of the Creative Commons Attribution License (https://creativecommons.org/licenses/by/4.0/) which permits unrestricted use, distribution, and reproduction in any medium, provided the original author and source are credited.
\end{abstract}

\section{Introduction}

Asthma and allergies are common throughout the world, including India, with high burden on morbidity and cost implications. Allergic rhinitis being one of the commonest allergic disorders affecting nearly $26 \%$ of the population in India, ${ }^{1}$ extracts a considerable toll on patients life, cognitive and learning functions, decision making and self perception associated with low energy levels. ${ }^{2}$

Allergic rhinitis can develop at any age and it is often associated with asthma and sinusitis. Upto $80 \%$ of children with asthma develop symptoms before the age of five and allergic rhinitis often precedes asthma. There is also growing evidence that allergic rhinitis is a risk factor for asthma. Thus, today, allergic rhinitis is considered a global

\footnotetext{
* Corresponding author.

E-mail address: poojaarora2312@rediffmail.com (P. Arora).
}

health issue with a considerable socio-economic impact, seriously affecting human productivity and qualify of life (QOL). In fact, the World Health Organization has also stepped up measures to increase the global awareness of allergic rhinitis and has introduced standard guidelines that would address effective treatment of rhinitis. Left untreated, allergic rhinitis can cause more serious conditions like asthma, sinusitis or ear infections. It is therefore important to decipher between allergies and colds. ${ }^{1}$

Air, without which the existence of life cannot be conceived, contains an array of biological particles including some like pollen, fungal spores and dust which may cause respiratory allergic disorders or precipitate their symptoms. In 1873, Sir Charles Harrison Blacklay for the first time reported that his own symptoms of seasonal allergic rhinitis were due to the pollen of grasses. He rubbed pollen into the skin of his arm and leg and elicited violent 
skin reactions, which probably was the first skin test with pollen. Subsequently aqueous extracts of pollen and other allergen. ${ }^{3}$

Allergy skin testing for immediate hypersensitivity is a cornerstone in the evaluation of patient with allergic disease and proper specific diagnosis is the foundation for successful management profile. Precise identification of allergens is worthwhile since it may lead to improvement in therapy. Skin Prick tests are done which are simple, quick and relatively cheap and have the advantage of providing the results while the patient is still in clinic. ${ }^{4,5}$

The dominant inhalant allergens differ in different parts of the world. Therefore, in this study an attempt was made to find out the common inhalant allergens causing allergy in patients in and around Saharanpur.

\section{Objective}

The objective of study is to document common air borne allergens in and around Saharanpur as a cause of allergic rhinitis by SPT, Serum IgE levels, absolute eosinophil count and Nasal smear eosinophils.

\section{Materials and Methods}

\subsection{Source of data}

This is a prospective study which included patients presenting with signs and symptoms suggestive of allergic rhinitis like nasal itching, sneezing, nasal discharge or blockade attending the Out Patient Departments of Government Medical College Saharanpur and nearby hospitals during the period from July 2018 to June 2019.

\subsection{Method of collection of data}

A complete clinical examination was carried out and detailed history about chief complaints, aggravating factors, associated allergy and family history of allergy and other relevant details were taken and documented in the proforma.

\subsection{Sample size}

1. Patients having symptoms of allergic rhinitis formed the study group.

\subsection{Inclusion criteria}

The clinically proven cases of allergic rhinitis i.e. the patients having symptoms of nasal itching, sneezing, discharge or blockade which occur for more than 1 hour on most days were included in study group.

\subsection{Exclusion criteria}

1. Patients with other causes of rhinitis like Vasomotor rhinitis were excluded.
2. Patients in whom complete work up was not possible were also excluded.

3. Patients in whom skin prick test was negative were also excluded.

I. With strict aseptic precautions blood samples (about $5 \mathrm{ml}$ ) were collected by venepuncture and transferred in sample collection vials.

a) EDTA vial for complete blood count, differential leucocyte count and absolute eosinophil count which were obtained using automated hematology analyzer and results were validated manually at Department of Pathology, Government Medical College and Hospital, Saharanpur.

b) Plain vial for total serum IgE levels. This was possible in 33 patients. Total IgE levels were estimated using automated chemiluminescence analyser, Advia centaur, Bayer diagnostics, USA. The normal levels of total serum IgE levels age wise are:

$<1$ year: < 52.3 IU/ml

$1-4$ years: $<351.6 \mathrm{IU} / \mathrm{ml}$

5-10 years: $<393.0 \mathrm{IU} / \mathrm{ml}$

11-15 years: $<170.0 \mathrm{IU} / \mathrm{ml}$

Adults: $<150.0 \mathrm{IU} / \mathrm{ml}$

II. Nasal smear for eosinophil count : Smears were made using nasal secretions, collected by asking the patient to blow out on the slide or by using cotton tipped nasal probe. Smears were air dried and stained by Giemsa stain. After staining, they were examined under oil immersion. Interpretation of nasal eosinophilia was done as per the following scale.

Table 1: Grading of nasal smear eosinophilia

\begin{tabular}{lll}
\hline- & $<5 \%$ Eosinophils & No Eosinophilia \\
+ & $10 \%$ Eosinophils & Slight Eosinophilia \\
++ & $11-50 \%$ Eosinophils & Moderate Eosinophilia \\
+++ & $>50 \%$ Eosinophils & Marked Eosinophilia \\
\hline
\end{tabular}

III. Skin prick tests were performed using the allergens selected after study of common flora and fauna in and around Saharanpur city. Tests were done in Department of Pathology, Government Medical College, Saharanpur. The allergens were obtained from Creative diagnostic Medicare Private Limited Mumbai.

Credisol Prick Test solutions are glycerinated aqueous allergen extracts prepared after the method of Coca. These solutions are standardized in Protein Nitrogen Units (PNU) per ml. Prick test solutions were supplied in glass vials - type I containing approximately $1.5 \mathrm{ml}$ of solutions sufficient for approximately 150 individuals tests. Vials were capped with polypropylene applicator which were coded according to the following chart.

Histamine was taken as the positive control and saline as negative control. The skin prick tests were performed on 50 patients as following. 


\begin{tabular}{lc} 
Pollen & Green \\
Fungi & Yellow \\
Dust mite & Orange \\
Insects & Red \\
Epithelial / Dander & Blue \\
Controls & White \\
\hline
\end{tabular}

Patients were asked to discontinue any medications that they were taking for allergic condition. Antihistamines and corticosteroids in high doses were asked to be discontinued 48 hours prior to testing. The test procedure consisted of cleaning the skin with isopropyl or $70 \%$ ethyl alcohol and allowing it to dry by evaporation. The areas chosen for doing the skin prick test were flexor surface of forearm and arm. The skin was marked with a ball point pen so as to identify and locate the site of each test. There was a difference of $2 \mathrm{~cm}$ in between the two test sites. A single drop of each test solution was placed. Skin prick test was performed using a sterile lancet. The lancet was placed through the drop of allergen extract at an acute angle to the skin and a shallow lift was made to elevate the small portion of epidermis without inducing bleeding. The lancet was raised for a second before skin was released. This was repeated for each drop of test solution. The lancet was carefully wiped on dry cotton wool in between the tests. Excess solution was removed by placing a tissue over the arm for moment.

The reactions were read after 15-20 minutes which appeared as raised wheal and erythema. Both wheal and erythema diameter were measured using a ruler supplied with the allergen kit and results expressed in $\mathrm{mm}$. Grading of skin prick test was done by comparison to a histamine positive control.

\begin{tabular}{ll}
\hline Grade & $\begin{array}{l}\text { Percent of Area of Wheal / Erythema } \\
\text { Induced by Histamine }\end{array}$ \\
+ & 25 \\
++ & 50 \\
+++ & 100 \\
++++ & 200 \\
\hline
\end{tabular}

After recording the results, the skin was wiped with surgical spirit and the patient was given a tablet of antihistamine to prevent any local reaction that may occur at the site of test.

\section{Results}

The total number of patient studied in this series is 50 . The age distribution of the patient ranged from 14 to 69 years. Majority of the patients belonged to second and third decades without sex predilection in our study. All patients subjected to SPT (46 allergens), nasal smear for eosinophil count and absolute eosinophil count in blood. Serum igE was done in 33 patients.
Absolute eosinophil count was raised in 56\% of the patients, while it was normal in $44 \%$ of the cases.

Table 2: Absolute eosinophil count

\begin{tabular}{lcc}
\hline & No. of Patients & Percentage \\
Noremal $(40-400)$ & 22 & 44 \\
Raised $(>440)$ & 28 & 56 \\
Total & 50 & 100 \\
\hline
\end{tabular}

Raised counts ranged from $450-1161$ cells $/ \mathrm{mm}^{3}$ and normal counts ranged from 226 to 430 cells $/ \mathrm{mm}^{3}$. Nasal smears for eosinophil was done in all included patient and result was tabulated in Table 3.

Table 3: Nasal smear for eosinophil count

\begin{tabular}{lcc}
\hline $\begin{array}{l}\text { Eosinophil Percentage in } \\
\text { smear }\end{array}$ & $\begin{array}{c}\text { No. of } \\
\text { Patients }\end{array}$ & Percentage \\
$<5 \%$ & 39 & 78 \\
$6-10 \%$ & 04 & 8 \\
$11-50 \%$ & 06 & 12 \\
$>50 \%$ & 01 & 2 \\
Total & 50 & 100 \\
\hline
\end{tabular}

Estimation of total serum IgE levels was possible in 33 patients. It was found to be raised in 32 patients (97\%). All patients were subjected to SPT with 46 allergens. Thus, a total of 2300 SPTs were done and response was tabulated in Table 4. Maximum numbers of positive $(2+, 3+, 4+)$ SPT was given by pollens in 40 patients $(80 \%)$, followed by dust in 35 patients (70\%). Mites and insects gave positive SPT in 26(52\%) and 25 (50\%) patients respectively, closely followed by fungi in $24(48 \%)$ patients. Least reaction was given by epithelia in $20 \%$ of patients.

Table 4: Positive skin prick test response to various groups of allergens

\begin{tabular}{lcc}
\hline Allergen Subgroups & No. of Patients & Percentage \\
Mite & 26 & 52 \\
Fungi & 24 & 48 \\
Pollens & 40 & 80 \\
Dust & 35 & 70 \\
Epithelia & 10 & 20 \\
Insects & 25 & 50 \\
\hline
\end{tabular}

Results of positive SPT with varied antigens were tabulated in table Tables 5, 6, 7, 8 and 9.

\section{Discussion}

The definitive diagnosis of nasal allergy requires identification of allergens and establishment of causal relationship between exposure to allergens and occurrence of relevant symptoms. Identification of allergens is possible by careful history taking and diagnostic procedure such as AEC, SPT, nasal eosinophil count and serum IgE level. 
Table 5: Results of positive skin tests with various pollen antigens tested

\begin{tabular}{lcc}
\hline Pollens & $\begin{array}{c}\text { No. of } \\
\text { Patients }\end{array}$ & Percentage \\
1. Cynodon dactylon & 20 & 40 \\
2. Parthenium hysterophorus & 35 & 70 \\
3. Sorghum vulgare & 0 & 0 \\
4. Pennisetum typhoides & 6 & 12 \\
5. Amaranthus spinosus & 20 & 40 \\
6. Argermone mexicana & 20 & 40 \\
7. Xanthium strumariuni & 0 & 0 \\
8. Brassica nigra & 15 & 30 \\
9. Ageratum conyzoides & 0 & 0 \\
10. Cocus nucifera & 0 & 0 \\
11. Peltophorum & 0 & 0 \\
pterocarpum & & \\
12. Eucalyputs spp. & 17 & 34 \\
13. Ricinus communis & 21 & 42 \\
14. Cassia siamea & 0 & 0 \\
15. Zea mays & 0 & 0 \\
16. Acacia Arabica & 0 & 0 \\
17. Prosopis juliflora & 16 & 32 \\
18. Carica papaya & 0 & 0 \\
19. Ipomoea sp. & 0 & 0 \\
20. Helianthus annus & 15 & 30 \\
21. Cassia occidentalis & 0 & 0 \\
22. Azadirachta indica & 0 & 0 \\
23. Mangifera Indica & 0 & \\
\hline
\end{tabular}

Table 6: Results of positive skin tests with four dusts tested

\begin{tabular}{lcc}
\hline Dust & No. of Patients & Percentage \\
Cotton Dust & 05 & 10 \\
House dust & 32 & 64 \\
Hay dust & 20 & 40 \\
Grain dust (Rice) & 06 & 12 \\
\hline
\end{tabular}

Table 7: Results of skin prick test with three mite allergens tested

\begin{tabular}{lcc}
\hline Mite & No. of Patients & Percentage \\
Mite (D-Farine) & 25 & 50 \\
Mite (D-Pteronyssinus) & 9 & 18 \\
Blomia sp. & 6 & 12 \\
\hline
\end{tabular}

Table 8: Results of positive skin prick test with antigenic extracts of various insects tested

\begin{tabular}{lcc}
\hline Insects & No. of Patients & Percentage \\
Ants & 0 & 0 \\
Cockroach & 14 & 28 \\
Housefly & 09 & 18 \\
Mosquito & 04 & 8 \\
\hline
\end{tabular}

Table 9: Results of positive skin prick test given by different fungal antigens tested

\begin{tabular}{lcc}
\hline Fungi & No. of Patients & Percentage \\
Aspergillus fumigatus & 0 & 0 \\
Aspergillus niger & 15 & 30 \\
Rhizopus nigricans & 4 & 8 \\
Penicillium Sp. & 5 & 10 \\
Candida albicans & 0 & 0 \\
Aspergillus versicolor & 4 & 8 \\
\hline
\end{tabular}

Table 10: Results of positive skin prick test with different epithelial antigens tested

$\begin{array}{lcc}\text { Epithelia } & \text { No. of Patients } & \text { Percentage } \\ \text { Dog epithelia } & 5 & 10 \\ \text { Sheep's wool } & 0 & 0 \\ \text { Human dander } & 0 & 0 \\ \text { Buffalo dander } & 7 & 14 \\ \text { Cat epithelia } & 3 & 6 \\ \text { Chicken feather } & 0 & 0\end{array}$

The purpose of the study was to determine and characterize common allergens using SPT in patients of allergic rhinitis in a tertiary centre and hospitals of Saharanpur, India

In the present study the majority of patients were in the second and third decades and very few patients in fifth and sixth decades, which is similar to studies done by Chaubey and Heda, ${ }^{6}$ Jha et al. ${ }^{7}$ and Gupta et al. ${ }^{8}$ Respiratory allergies commence early in the life and tend to become less frequent as age advances.

There is increase in incidence of allergy in younger age groups which may be due to more exposure of younger generations to environmental pollution which is increasing day by day.

Absolute eosinophil count was found to be raised in 56\% of the patient where it ranged from 450 to $1161 \mathrm{cells} / \mathrm{mm}^{3} \mathrm{In}$ patients who had normal counts (44\%) absolute eosinophil count levels ranged from 226 to 430 cells $/ \mathrm{mm}^{3}$. Singh and Chaymal $^{9}$ found absolute eosinophil count to be raised in only 8 out of 30 patients $(26.6 \%)$ and a level of not more than 600 cells $/ \mathrm{mm}^{3}$ was noted. According to study done by Chaubey and $\mathrm{Heda}^{6}$ blood eosinophil counts ranged between 1 to $8 \%$ in $82 \%$ of the patients and in $6 \%$ of patients it was more than $10 \%$. Thus absolute eosinophil count level is not raised in all the patients of allergic rhinitis as found in our study and other studies.

In the present study, nasal smear positivity for eosinophils was seen in $22 \%$ of cases while in remaining $78 \%$ of the cases it was either negative or less than $5 \%$. Sood ${ }^{10}$ found nasal smear positivity in $80 \%$ of the patients, Chaubey and Heda ${ }^{6}$ found in $45 \%$ of cases, Wheldon et al. ${ }^{11}$ reported in $30 \%$ of patients and in the present study it was seen in $22 \%$ of the patients only. This may be due to, as pointed out by Wheldon et al., ${ }^{11}$ because of difficulty 
in collection of specimens, timing of sample collection and other variables which influence the presence of eosinophils in the nasal smear.

In our study total serum IgE level measurements were possible in 33 patients. It was found to be raised in 32 patients (97\% of cases). It has been argued that elevated IgE level have a high correlation with the pressure of inhalant allergy. King et al. ${ }^{12}$ noted that $99 \%$ of patients who had total IgE levels greater than 400 units/ml were positive for allergy as determined by RAST. Whereas only $33 \%$ of the patients who had total IgE level of less than 10 units $/ \mathrm{ml}$ had significant allergy as determined by RAST. Although high levels of total IgE are predictive of significant allergy, low levels do not rule out clinically important allergic disease. Total IgE levels, therefore are not reliable indicators of absence of significant allergy. High positivity (97\%) with respect to total $\operatorname{IgE}$ levels can be attributed to testing methodology used (Chemiluminscence Immunoassay) and rigid inclusion and exclusion criteria.

The most common allergens found in our study with the help of SPT were pollen (80\%), dust (70\%), mite $(52 \%)$, insects(50\%), fungi(48\%) and epithelial antigen $(20 \%)$ overall, pollen of Parthenium (70\%) followed by house dust $(64 \%)$ were found to be the most common offending allergens.

The most common allergen in our study was pollen $(80 \%)$ and most common among all pollen was pollen of Parthenium, similar to study done by Chaubal and Gadve $^{13}$ and it was found to be the second most common allergen after Amaranthus in Bangalore in a study conducted by Anand and Agashi. ${ }^{14}$ Next common offending pollen antigen noted was the pollen of Ricinus in $42 \%$ of the patients. This pollen was found to be the commonest offending allergen by Pherwani et al. ${ }^{15}$

Next common group of allergens after pollen antigens that gave positive reaction was dust in $70 \%$ of patients. Among the dust allergens maximum number of positive skin reaction were given by house dust in 32 patients, followed by hay dust in 20 patients, cotton and grain dust (rice) in 6 and 5 patients respectively. House dust was found to give maximum number of positive skin reactions which was similar to study done by Jha et al. ${ }^{7}$ It was found to be the second most common offending dust in a study done by Sethi $\mathrm{S}$ et al., ${ }^{16}$ Pherwani et al. ${ }^{15}$ and Shanker et al. ${ }^{17}$ Raju et al. ${ }^{18}$ found grain dust as the most common offending dust, followed by cotton, hay and then house dust. This could be due to difference in climatic condition and the other environmental factors of the area where the study was conducted.

House dust mite (D.farine) gave positive reactions in 25 patients $(50 \%)$ and $D$-Pteronyssius in 9 patients $(18 \%)$ and Blomia species in $6(12 \%)$ patients in the present study. House dust mite (D.farine) gave positive reaction in $50 \%$ of the patients while Singh and Chamyal ${ }^{9}$ reported in $43.3 \%$, Raju et al. ${ }^{18}$ in $40 \%$ and Pherwani et al. ${ }^{15}$ in $31.3 \%$ of the patients.

In our study cockroach extract gave positive reaction in $28 \%$ of the patients, followed by housefly extracts in $18 \%$ of the patients and mosquito extracts in $8 \%$ of the patients. A maximum number of positive prick test response was given by Cockroach which is similar to study done by Pherwani et al ${ }^{15}$ and Chew FT et al. ${ }^{19}$ Raju et al, ${ }^{18}$ and Shanker et al ${ }^{17}$ reported maximum number of positive skin reactions in housefly followed by mosquito and cockroach extracts.

Six fungal extracts were used as allergens among which positive reaction was given by four fungal extracts, namely Aspergillus niger in 15 patients (30\%), Aspergillus versicolor and Rhizopus nigricans in four patients each and Penicillum species in five patients. Prasad et al. ${ }^{20}$ In their study by SPT in Lucknow found marked positivity to Aspegillus spp., A.tenuis, F.solani. and R. Nigricans. Epithelial allergens as a group gave the least positive reaction in only $20 \%$ of the cases. Positive reaction was given by buffalo dander in 7 patients, dog epithelia in 5 patients and cat epithelia in 3 patients. No reaction was given by sheep wool, human dander and chicken feather extracts. Buffalo dander was the most common allergen identified which is in accordance with a study done by Gupta et al. ${ }^{21}$ is probably because most of the patients were from rural area.

The knowledge of common allergens found among study population in our region could assist medical practitioners in narrowing down the panel of allergens tested in daily practice leading to more specificity and cost-effectiveness.

Thus specific allergy test, including skin tests and specific $\operatorname{lgE}$ measurements are typically more useful compared to nasal smear eosinophils and AEC levels in the diagnosis and treatment of allergic rhinitis.

\section{Source of Funding}

None.

\section{Conflict of Interest}

None.

\section{References}

1. Pawankar R. Evidence based guidelines. Allergic rhinitis and its impact on asthma. An update. Japan: ARIA, WHO Initiative; 2001.

2. Fineman SM. The burden of allergic rhinitis; beyond dollars and cents. Ann Allergy Asthma Immunol. 2002;88(4):2-7.

3. Agarwal MK. Skin testing and respiratory allergic disorders. Indian J Chest Dis Allied Sci. 1986;28(4):179-82.

4. Mccann WA, Ownby DR. The reproducibility of the allergy skin test scoring and interpretation by board certified/board- eligible allergist. Ann Allergy Asthma Immunol. 2002;89:368-71.

5. Evan PW. Allergic rhinitis. In: Lachman PJ, Peter SK, Rosen FS, Walport MJ, editors. Clinical aspects of immunology. Boston: Blackwell Scientific Publication; 1993. p. 1049-66.

6. Chaubey BS, Heda HR. Clinical study of respiratory allergy. Indian J Chest Dis. 1973;15(2):108-16. 
7. Jha VK, Sundaramma M, Mishra SK, Joshi M. Clinical studies with some airborne pollens and dusts as respiratory allergens around Varanasi. Indian J Chest Dis. 1975;17(3):107-12.

8. Gupta MC, Mittal OP, Katyar SK. Pollen allergy in Kanpur. Aspects Allergy App Immunol. 1984;17:99-105.

9. Singh RB, Chamyal PC. Skin test and specific immunotherapy in allergic rhinitis. Indian $J$ Otolaryngol Head Neck Surg. 1994;3(3):138-41.

10. Sood A. Diagnostic significance of nasal eosinophillia in allergic rhinitis. Indian J Otolaryngol Head Neck Surg. 2005;57(1):13-6.

11. Whelan CFA. Problems in the examination of nasal smears in allergic rhinitis. J Laryngol Otol. 1980;94:399-404.

12. King JH, Stachler RJ, Shah A. Current in vivo and in vitro screens for inhalant allergy. Otolaryngol Clin N Am. 2003;36(5):855-68.

13. Chaubal PD, Gadve SB. Study of pollen allergy in Kolhapur during monsoon. Indian J Chest Dis All Sci. 1984;26(1):38-40.

14. Anand P, Agashe SN. Immunological approach to extra mural environmental naso-bronchial allergy. Indian $J$ Otolaryngol. 1984;36(2):39-44.

15. Pherwani AV, Desai AG, Bhave SY. An analysis of skin prick test reactions in asthmatic children in Bombay. Indian J Chest Dis Allied Sci. 1985;27(4):219-24.

16. Sethi S, Sarkar B, Gupta SR. A study of intradermal allergy testing in bronchial asthma. Indian J Chest Dis and All Sci. 1986;28(3):105-18.

17. Shanker A, Jain PC, Kumar U. A study of indentification of offending allergens in patients of bronchial asthma in Gwalior attending J.A. group of hospitals. Indian J Chest Dis Allied Sci. 1979;21(4):166-73.

18. Raju B, Kotilingam K, Rao RM, Rao SG, Bharani SA. Allergic Skin tests in extrinsic asthmatics in Visakhapatnam - A pilot study. Lung India. 1990;8(2):79-83.

19. Chew FT, Lim SH, Goh DY, Lee BW. Sensitization to local dustmite fauna in Singapore. Allergy. 1999;54(11):1150-9.

20. Prasad R, Verma SK, Dna R, Kant S, Kushwalia RA, Agarwal SP A study of skin sensitivity to various allergens by skin prick test in patients of nasobronchil allergy. Lung India. 2009;26:70-3.

21. Gupta N, Goyal M, Dixit R, Agrawal M, Meena M, Kuldeep R. Allergen sensitization profile in patients of nasobronchial allergy form rural and urban area of residence in central Rajasthan. J Evid Based Med Health. 2018;5:588-92.

\section{Author biography}

Pooja Arora, Assistant Professor

Cite this article: Arora P. A study of various diagnostic tests to identify offending allergens in patients of allergic rhinitis in a tertiary care centre in northern India. Indian J Pathol Oncol 2021;8(2):254-259. 